\title{
Sistem Pemantauan Derajat Keasaman Limbah Air Pada Areal Tambang Berbasis Nirkabel Menggunakan Protokol Lora (Studi Kasus : PT. Wanatiara Persada)
}

\author{
Febrian Nanda $P^{1}$, Tjahjanto ${ }^{2}$
}

\author{
${ }^{1}$ Universitas Budi Luhur, Jl. Ciledug Raya, Petukangan Utara, Jakarta Selatan, 12260, DKI Jakarta, Indonesia \\ e-mail:1811601283@student.budiluhur.ac.id ${ }^{* 1}$,cahyanto@budiluhur.ac.id ${ }^{2}$
}

\begin{tabular}{|c|c|}
\hline INFORMASI ARTIKEL & A B S T R A K \\
\hline $\begin{array}{l}\text { Sejarah Artikel: } \\
\text { Diterima Redaksi : } 25 \text { Maret } 2021 \\
\text { Revisi Akhir : } 20 \text { Agustus } 2021 \\
\text { Diterbitkan Online : } 22 \text { Agustus } 2021\end{array}$ & $\begin{array}{l}\text { PT. Wanatiara Persada adalah perusahaan yang bergerak di bidang pertambangan nikel } \\
\text { yang berlokasi di Propinsi Maluku Utara. Dalam kegiatan pertambangan tersebut tentu } \\
\text { akan berdampak terhadap lingkungan, terutama terhadap kualitas air baik air sungai, } \\
\text { maupun air laut. Dalam pembuangan limbah air ke laut perlu di lakukan uji derajat } \\
\text { keasaman yang sesuai standar yang ditentukan oleh Menteri Lingkungan Hidup, yang }\end{array}$ \\
\hline $\begin{array}{l}\text { Kata Kunci : } \\
\text { pH Monitoring, Arduino, Raspberry, IoT, } \\
\text { LoRa, Monitoring Limbah Air, Limbah Air }\end{array}$ & $\begin{array}{l}\text { mana standar tersebut tertuang pada Peraturan Menteri Lingkungan Hidup No.9 Tahun } \\
2006 \text { tentang baku mutu air limbah bagi usaha dan/ atau kegiatan pertambangan bijih } \\
\text { nikel, sedangkan untuk melakukan pengukuran saat ini ketersediaan peralatan sangat } \\
\text { terbatas serta lokasi kantor / living area jauh dengan kolam pengendap sehingga terimbas }\end{array}$ \\
\hline $\begin{array}{l}\text { Korespondensi : } \\
\text { Telepon / Hp : +62 81289552015 } \\
\text { E-mail : 1811601283@budiluhur.ac.id }\end{array}$ & $\begin{array}{l}\text { sebelum di lakukan pembuangan ke air laut. Solusi dari permasalahan tersebut adalah } \\
\text { dibuatkan alat untuk memantau derajat keasaman limbah air pada kompartemen kolam } \\
\text { pengendap (sediment pond) secara realtime dengan memanfaatkan Arduino dengan } \\
\text { sensor pH yang membaca derajat keasaman yang mana data sensor tersebut dikirimkan } \\
\text { melalui nirkabel menggunakan LoRa pada Arduno penerima, sehingga dapat } \\
\text { mempermudah dalam melakukan monitoring dari masalah jarak living area dengan area } \\
\text { pengendap lumpur (Sedimend Pond). Metode penelitian yang di gunakan dalam } \\
\text { penelitian ini adalah penelitian kuantitatif dengan metode eksperimental. Dipilihnya } \\
\text { metode penelitian ini adalah karena metode ini cocok dengan penelitian yang diangkat } \\
\text { yaitu pengembangan sebuah prototype dan melakukan penelitian berupa ekseperimen } \\
\text { terhadap objek penelitian (Limbah Air). }\end{array}$ \\
\hline
\end{tabular}

\section{PENDAHULUAN}

PT. Wanatiara Persada, adalah salah satu perusahaan Penanaman Modal Asing (PMA) yang bergerak di bidang pertambangan serta pengolahan dan pemurnian bijih nikel. Kegiatan pertambangan PT. Wanatiara Persada berada di dalam kawasan hutan produksi dan menggunakan sistem tambang terbuka (open pit). Dalam kegiatan pertambangan tersebut tentu akan berdampak terhadap lingkungan. Saat ini terdapat beberapa kompartemen kolam pengendap (sediment pond) untuk mengendapkan lumpur yang tererosi bersama air hujan (limbah air) yang akan dibuang ke laur.

Dalam pembuangan limbah air ke laut perlu di lakukan uji serajat keasaman yang sesuai standar yang ditentukan oleh Menteri Lingkungan Hidup, sedangkan untuk melakukan pengukuran ketersediaan peralatan sangat terbatas serta lokasi kantor / living area kurang lebih 2-3 $\mathrm{km}$ dengan kolam pengendap sehingga terimbas pada kurangnya pemantauan baku mutu air sedangkan menurut aturan Permen LH No. 9 Tahun 2006 Pasal 10 Point (a), perlu dilakukan swapantau harian. Jadi permasalahannya adalah pemantauan derajat keasaman limbah air pada kolam pengendap tidak dapat di lakukan setiap hari sebelum di lakukan pembuangan ke air laut. Dalam penulisan penelitian ini, penulis akan menyajikan inovasi sebuah sistem yang dapat memantau derajat keasaman limbah air pada kompartemen kolam pengendap (sediment pond) dengan sitem pemantauan derajat keasaman berbasis nirkabel dengan protokol LoRa. Manfaat dari penelitian ini diharapkan dapat menjawab permasalah jarak antara kantor / living area dengan area pengendap lumpur (Sedimend Pond) dalam pemantauan derajat keasaman.

Pada penelitian sebelumnya yang di lakukan oleh [1] yang berjudul "Wastewater monitoring system in industrial workshop based on wireless sensor network" bahwa dalam keberhasilan pengukuran derajat keasaman adalah di lakukan kalibrasi sensor, memperhatikan perubahan suhu sekitar, voltase yang dialirkan pada sensor harus setabil, memastikan bahwa desain sirkuit harus diperhatikan sehingga tidak terdapat gangguan pengiriman data.

Metode penelitian yang di gunakan dalam penelitian ini adalah penelitian kuantitatif dengan metode eksperimental dan metode QoS dalam analisis performa LoRa. Dipilihnya metode penelitian ini adalah karena metode ini cocok dengan penelitian yang diangkat yaitu pengembangan sebuah prototype dan melakukan penelitian berupa ekseperimen terhadap objek penelitian (Air Limbah ) [2], [3]. 


\section{Dasar Teori}

\subsection{Sensor}

Sensor adalah alat untuk mendeteksi atau mengukur sesuatu, yang di gunakan untuk mengubah variasi mekanis, magnetis, panas, sinar dan kimia menjadi tegangan dan arus listrik [4]. Sensor kimia adalah penganalisis yang merespons analit tertentu dengan cara yang selektif dan dapat dibalik dan mengubah kuantitas kimia masukan, mulai dari konsentrasi komponen sampel tertentu hingga analisis komposisi total, menjadi sinyal analitik listrik [5].

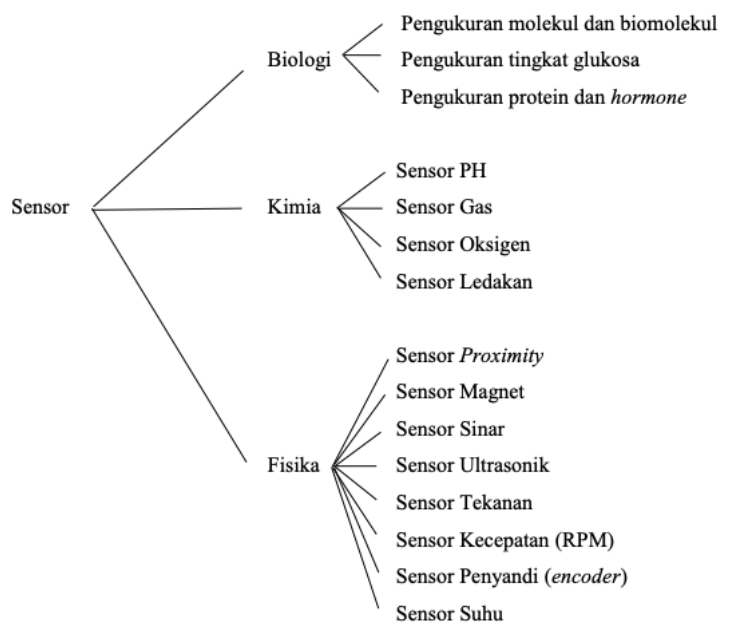

Gambar 1. Bagan Sensor

Subjek sensor kimia merupakan disiplin ilmu yang dibentuk oleh studi multidisiplin antara lain kimia, biologi, kelistrikan, optik, mekanika, akustik, termologi, teknologi semikonduktor, teknologi mikroelektronika, dan teknologi membran.

\subsection{Power of Hydrogen (pH)}

$\mathrm{pH}$ adalah suatu satuan ukur yang menguraikan derajat tingkat kadar keasaman atau kadar alkali dari suatu larutan. Unit pH diukur pada skali 0 sampai 14 [6]. Istilah $\mathrm{pH}$ berasal dari "P" lambang matematika dari negative logaritma, dan " $\mathrm{H}$ " lambing kimia untuk unsur hydrogen. Definisi yang formal tentang $\mathrm{pH}$ adalah negative logaritma dari aktivitas ion Hidrogen.

\subsection{Arduino Uno}

Arduino adalah kit elektronik atau papan rangkaian elektronik open source yang di dalamnya terdapat komponen utama yaitu sebuah chip mikrokontroler dengan jenis AVR dari perusahaan Atmel [7]. Mikrokontroler itu sendiri adalah chip atau IC (integrated circuit) yang bisa diprogram menggunakan komputer. Tujuan menanamkan program pada mikrokontroler adalah agar rangkaian elektronik dapat membaca input, memproses input tersebut dan kemudian menghasilkan output sesuai yang diinginkan.

\subsection{LoRa}

LoRa Spread Spectrum adalah modulasi yang dipatenkan yang dikembangkan oleh Semtech (https //ww.sentech.com/) berdasarkan modulasi Chirp Spread Spectrum (CSS). LoRa (kependekan dari "long range") yang mana menggunakan konsumsi daya jangka panjang dan rendah, data rate rendah, dan data yang aman [8]. LoRa memungkinkan komunikasi jarak jauh antara dua perangkat yang memiliki keterbatasan sumber daya. Untuk penggunaan LoRa di Indonesia, penggunaan LoRa saat ini masih dalam kajian dan memungkinkan di gunakan pada frekuensi tidak berlisensi yaitu pada $923 \mathrm{Mhz}$ sampai 925 Mhz. Frekuensi tersebut dipilih agar tidak mengganggu operasional dari jaringan seluler [9].

\section{ANALISIS DAN PENGUJIAN PENELITIAN}

Pengujian instrument pemantauan derajat keasaman limbah air ini dilakukan dengan metode riset eksperimental dengan metode analisis Quality Of Service, peneliti meletakkan arduino pengirim yang terpasang sensor dan modul lora. Arduino pengirim ini akan mengirimkan data derajat keasaman yang dikirimkan melalui wireless, data sensor tersebut akan diterima oleh arduino penerima yang juga terpasang modul lora.

\subsection{Analisis QoS Terhadap Performa LoRa}

Pada penelitian ini peneliti menganalisis spreading factor ( $\mathrm{sf}$ ) dan perubahan jarak dengan menggunakan metode QoS dengan modul lora yang memiliki frekuensi 433 Mhz. Dengan jarak yang sudah ditentukan yaitu 10, 50, 100 Meter dalam kondisi non line of sight (NLOS) dan nilai SF di tetapkan pada angka 7-12. Parameter QoS yang diukur termasuk packet loss, time on air, dan throughput. Dengan adanya analisis ini diharapkan dapat merekomendasikan nilai spreading factor ( $\mathrm{sf}$ ) yang tepat agar transmisi LoRa berjalan dengan lancar dalam pengiriman atau penerimaan data sensor berdasarkan QoS dalam jarak tertentu. Parameter QoS yang diuji pada penelitian ini adalah packet loss, time on air, dan throughtput.

Menurut [10] packet loss diukur dengan membandingkan paket yang dikirim oleh klien dan paket yang diterima oleh gateway pada proses data polling. Throughput diukur dengan membandingkan bit yang diterima dengan waktu yang telah berlalu. Time on Air diukur dengan menghitung waktu yang dibutuhkan untuk mengirimkan 1 paket dari client ke gateway. Persamaan yang digunakan untuk efektivitas packet loss, throughput, dan data transfer dapat dilihat pada persamaan (1), (2), dan (3). 
Febrian Nanda P, Tjahjanto, Sistem Pemantauan Derajat Keasaman Limbah Air Menggunakan Protokol Lora 3

Packet Loss $=($ Packet Sent - Packet Received $) * 100 \%$

Time On Air $=$ Receive Time - Send Time

Mengacu pada kondisi area penelitian pada areal tambang maka, implementasi lora pada kondisi diluar ruangan yang terdapat pohon atau bangunan. Menurut (Jansen C. Liando, 2019) pengujian kondisi NLOS cocok untuk kondisi lingkungan outdoor. Kondisi NLos merupakan kondisi dimana antara pemancar dan penerima terdapat halangan seperti pohon, pilar, rumah, bangunan. Dari hal tersebut maka peneliti membuat pengujian Nlos dengan jarak 10, 50, dan 100 meter. Dalam melakukan pengujian peneliti melakukan penggantian Spreading factor (sf) dari 7 sampai 12, hasil dari pengujian tersebut untuk mengetahui packet loss, time on air, dan throughtput.

\subsection{Percobaan Pengiriman Data Sensor}

Berikutnya adalah melakukan pengujian penerimaan data sensor, peneliti menyiapkan beberapa simulasi uji jarak yang telah ditentukan oleh peneliti yang telah dikonsultasikan dengan tenaga ahli dibidang ilmu tanah yaitu bapak Tjakra Nusantara. Dalam melakukan pengujian peneliti menyiapkan dua lokasi yaitu tanah lapang dan area perumahan dengan waktu uji tiap titik adalah 5 menit dengan nilai sf 7

\section{HASIL PENGUJIAN DAN ANALISIS}

Dari hasil pengujian Nlos didapatkan hasil thoughput yang dapat dilihat pada tabel dibawah ini:

\begin{tabular}{|c|c|c|c|c|}
\hline Distance & Sf & $\begin{array}{c}\text { Packet } \\
\text { Received }\end{array}$ & $\begin{array}{c}\text { Elapse } \\
\text { Time (S) }\end{array}$ & $\begin{array}{c}\text { Throughput } \\
\text { (Bit/S) }\end{array}$ \\
\hline \multirow[t]{6}{*}{10} & SF7 & 30 & 0.369 & 81.32 \\
\hline & SF8 & 30 & 0.331 & 90.71 \\
\hline & SF9 & 30 & 0.384 & 78.14 \\
\hline & $\begin{array}{c}\text { SF1 } \\
0\end{array}$ & 30 & 0.477 & 62.86 \\
\hline & $\begin{array}{c}\text { SF1 } \\
1\end{array}$ & 30 & 0.676 & 44.39 \\
\hline & $\begin{array}{c}\text { SF1 } \\
2 \\
\end{array}$ & 30 & 1.089 & 27.56 \\
\hline \multirow[t]{6}{*}{50} & SF7 & 17 & 0.027 & 636.13 \\
\hline & SF8 & 30 & 0.048 & 622.41 \\
\hline & SF9 & 30 & 0.095 & 317.24 \\
\hline & $\begin{array}{c}\text { SF1 } \\
0\end{array}$ & 30 & 0.187 & 160.60 \\
\hline & $\begin{array}{c}\text { SF1 } \\
1\end{array}$ & 30 & 0.396 & 75.82 \\
\hline & $\begin{array}{c}\text { SF1 } \\
2\end{array}$ & 30 & 0.812 & 36.94 \\
\hline \multirow[t]{4}{*}{100} & SF7 & 29 & 0.027 & 1063.21 \\
\hline & SF8 & 30 & 0.019 & 1607.14 \\
\hline & SF9 & 30 & 0.034 & 870.41 \\
\hline & $\begin{array}{c}\text { SF1 } \\
0\end{array}$ & 30 & 0.124 & 241.09 \\
\hline
\end{tabular}

\begin{tabular}{cccc}
$\begin{array}{c}\text { SF1 } \\
1\end{array}$ & 30 & 0.328 & 91.57 \\
\hline $\begin{array}{c}\text { SF1 } \\
2\end{array}$ & 30 & 0.400 & 75.02 \\
\hline
\end{tabular}

Dari hasil pengujian Nlos dalam jarak 10, 50 dan 100 meter dapat dilihat bahwa semakin besar nilai sf maka throughtput bit per detik akan turun, hasil throughtput juga dapat dilihat pada grafik dibawah ini :

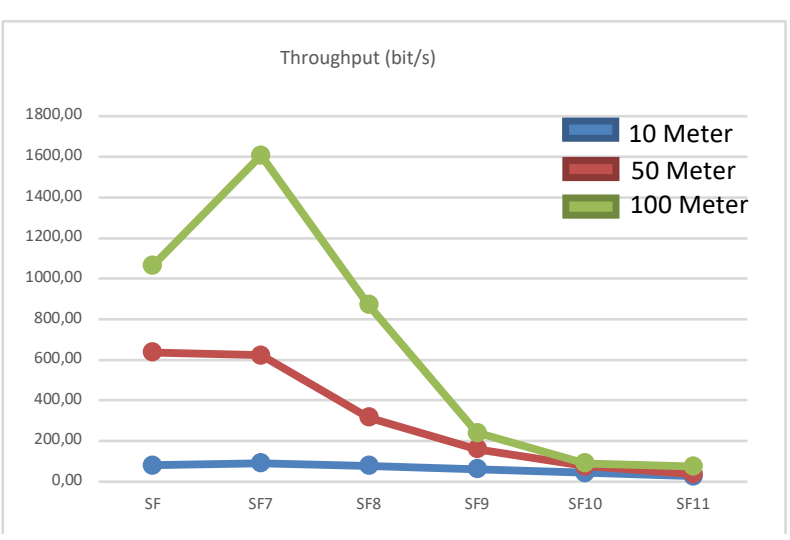

Gambar 2 Hasil Throughput

Tahap berikutnya adalah hasil pengujian Nlos dengan parameter packet loss, Pengukuran packet loss untuk mengetahui prosentase kehilangan paket yang diterima. Hasil uji dapat dilihat pada tabel dibawah ini:

Tabel 2. Hasil Packet Loss Pengujian Nlos

\begin{tabular}{|c|c|c|c|c|}
\hline Distance & Sf & $\begin{array}{c}\text { Packet } \\
\text { Sent }\end{array}$ & $\begin{array}{c}\text { Packet } \\
\text { Received }\end{array}$ & $\begin{array}{c}\text { Packet } \\
\text { Loss }\end{array}$ \\
\hline \multirow[t]{6}{*}{10} & SF7 & 30 & 30 & $0 \%$ \\
\hline & SF8 & 30 & 30 & $0 \%$ \\
\hline & SF9 & 30 & 30 & $0 \%$ \\
\hline & $\begin{array}{c}\text { SF1 } \\
0\end{array}$ & 30 & 30 & $0 \%$ \\
\hline & $\begin{array}{c}\text { SF1 } \\
1\end{array}$ & 30 & 30 & $0 \%$ \\
\hline & $\begin{array}{c}\text { SF1 } \\
2\end{array}$ & 30 & 30 & $0 \%$ \\
\hline \multirow[t]{6}{*}{50} & SF7 & 30 & 17 & $13 \%$ \\
\hline & SF8 & 30 & 30 & $0 \%$ \\
\hline & SF9 & 30 & 30 & $0 \%$ \\
\hline & $\begin{array}{c}\text { SF1 } \\
0 \\
\end{array}$ & 30 & 30 & $0 \%$ \\
\hline & $\begin{array}{c}\text { SF1 } \\
1 \\
\end{array}$ & 30 & 30 & $0 \%$ \\
\hline & $\begin{array}{c}\text { SF1 } \\
2\end{array}$ & 30 & 30 & $0 \%$ \\
\hline \multirow[t]{6}{*}{100} & SF7 & 30 & 29 & $1 \%$ \\
\hline & SF8 & 30 & 30 & $0 \%$ \\
\hline & SF9 & 30 & 30 & $0 \%$ \\
\hline & $\begin{array}{c}\text { SF1 } \\
0\end{array}$ & 30 & 30 & $0 \%$ \\
\hline & $\begin{array}{c}\text { SF1 } \\
1 \\
\end{array}$ & 30 & 30 & $0 \%$ \\
\hline & $\begin{array}{c}\text { SF1 } \\
2\end{array}$ & 30 & 30 & $0 \%$ \\
\hline
\end{tabular}


Hasil pengujian berikutnya adalah Time on Air, Time on Air (ToA) adalah berapa waktu yang dibutuhkan lora untuk menerima paket, berikut adalah tabel hasil dari ToA.

Tabel 3. Hasil Time on Air Pengujian Nlos

\section{Distance Sf Time On Air}

(S)

\begin{tabular}{ccc}
\hline \multirow{10}{*}{10} & SF7 & 0.369 \\
\cline { 2 - 3 } & SF8 & 0.331 \\
\cline { 2 - 3 } & SF9 & 0.384 \\
\cline { 2 - 3 } & SF10 & 0.477 \\
\cline { 2 - 3 } 50 & SF11 & 0.676 \\
\cline { 2 - 3 } & SF12 & 1.089 \\
\hline \multirow{7}{*}{$\mathbf{5 0}$} & SF7 & 0.027 \\
\cline { 2 - 3 } & SF8 & 0.048 \\
\cline { 2 - 3 } & SF9 & 0.095 \\
\cline { 2 - 3 } & SF10 & 0.187 \\
\cline { 2 - 3 } & SF11 & 0.396 \\
\cline { 2 - 3 } & SF12 & 0.812 \\
\hline & SF7 & 0.027 \\
\cline { 2 - 3 } & SF8 & 0.019 \\
\cline { 2 - 3 } & SF9 & 0.034 \\
\hline & SF10 & 0.124 \\
\hline & SF11 & 0.328 \\
\hline & SF12 & 0.400 \\
\hline & & \\
& & SF
\end{tabular}

Dari hasil tabel diatas diketahui bahwa semakin besar nilai sf maka waktu yang dibutuhkan untuk mengirimkan paket semakin besar pula waktu yang akan ditempuh. Hasil ToA dapat digambarkan pada grafik dibawah ini:

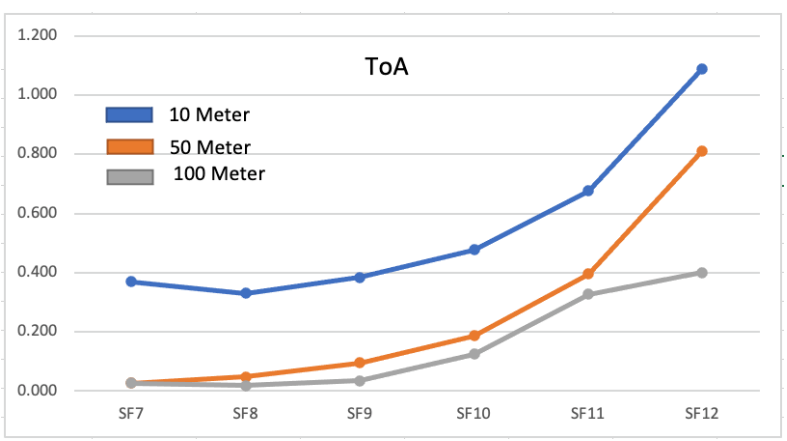

Gambar 3. Grafik Hasil Time on Air (ToA) Pengujian Nlos

Berikutnya adalah hasil pengujian penerimaan data sensor, perangkat arduino pengirim deletakkan pada lokasi yang ditentukan sedangkan perangkat penerima juga diletakkan pada lokasi yang telah ditentukan jaraknya. setelah dilakukan pengujian pada lokasi yang telah ditentukan didapatkan hasil yang dapat dilihat pada tabel dibawah ini

Tabel 4. Hasil Pengujian Penerimaan Data Sensor

\begin{tabular}{|c|c|c|c|c|c|c|c|}
\hline Lokasi & $\begin{array}{l}\text { JARA } \\
\mathrm{K}(\mathrm{m})\end{array}$ & $\begin{array}{l}\text { ELEVASI } \\
(\mathrm{m})\end{array}$ & TX & $\mathrm{RX}$ & $\begin{array}{c}\text { RSSI } \\
(\mathrm{dB} \\
\mathrm{m})\end{array}$ & $\begin{array}{l}\text { Init } \\
\text { (s) }\end{array}$ & Status \\
\hline $\begin{array}{l}\text { P. Kota } \\
\text { Sutera }\end{array}$ & 405 & 9 & $\checkmark$ & $\checkmark$ & -108 & 37.3 & Sukses \\
\hline $\begin{array}{l}\text { P. Kota } \\
\text { Sutera }\end{array}$ & 269.3 & 10 & $\checkmark$ & $\checkmark$ & -101 & 24.7 & Sukses \\
\hline $\begin{array}{l}\text { P. Kota } \\
\text { Sutera }\end{array}$ & 534.2 & 10 & $\checkmark$ & $\checkmark$ & -106 & 47.4 & Sukses \\
\hline $\begin{array}{l}\text { P. Kota } \\
\text { Sutera }\end{array}$ & 668.7 & 10 & $\checkmark$ & $\checkmark$ & -107 & 63.3 & Sukses \\
\hline $\begin{array}{l}\text { P. Kota } \\
\text { Sutera }\end{array}$ & 763.1 & 10 & $\checkmark$ & $\mathrm{x}$ & -109 & 0 & Gagal \\
\hline $\begin{array}{c}\text { T. } \\
\text { Sindangsar }\end{array}$ & 838 & 10 & $\checkmark$ & $\mathrm{x}$ & 0 & 0 & Gagal \\
\hline
\end{tabular}

\section{KESIMPULAN}

Dari pengujian kondisi Nlos pada jarak 10,50 dan 100 meter dengan SF 7 sampai 12 adalah pertama bila jarak semakin menjauh maka terdapat kemungkinan packet akan hilang hal tersebut dapat dilakukan dengan melakukan penggantian nilai sf ke nilai lebih besar, akan tetapi dari pengujian time on air (ToA) semakin besar nilai sf maka nilai waktu terima akan besar pula begitu juga dengan hasil throughput apabila nilai sf sebakin besar maka nilai bit per detik akan menurun. Sehingga peneliti menyarankan agar menyesuaikan tempat yang akan di implementasikan, apabila jarak lebih dari 100 meter maka menurut peneliti adalah melakukan penggantian nilai sf semakin besar, walaupun waktu tempuh packet lebih lama akan tetapi packet tetap akan diterima dengan baik dan apabila akan di implementasikan pada jarak pendek maka dapat dilakukan penggantian nilai sf yang lebih kecil.

Dari hasil penerimaan data sensor yang dilakukan oleh peneliti yang juga mengacu pada hasil uji performa LoRa dengan melakukan penggantian nilai sf maka dapat disimpulkan bahwa dalam keberhasilan dalam mendapatkan hasil pemantuan derajat keasaman limbah air yang menggunakan protokol lora adalah perlunya pertimbangan dalam menentukan nilai sf berdasakan jarak yang akan di implementasikan, kondisi jarak sangat mempengaruhi dalam proses pengiriman dan penerimaan data sensor selain itu juga pohon atau benda padat juga berpengaruh dalam proses pengiriman dan penerimaan packet, apabila terdapat benda-benda padat dapat mempengaruhi transmisi data, sehingga packet yang diterima dapat kurang setabil sehingga perlu dilakukan peningkatan kualitas antena lora dari 
sisi arduino pengirim maupun arduino penerima dan ada juga faktor lain yang berpengaruh seperti tingginya antenna pada LoRa.

\section{DAFTAR PUSTAKA}

[1] M. Zhang and S. She, "Wastewater monitoring system in industrial workshop based on wireless sensor network," Int. J. Online Eng., vol. 13, no. 3, pp. 63-74, 2017.

[2] R. M. Jaya and D. Hirawan, "Prototype Monitoring Pengolahan Air Limbah Industri Farmasi Berbasis Internet of Things ( Studi Kasus : Pt . Otto Pharmaceutical Industries )."

[3] D. A. A. Novitasari, D. Triyanto, and I. Nirmala, "Rancang Bangun Sistem Monitoring pada Limbah Cair Industri Berbasis Mikrokontroler dengan Antarmuka Website," Coding J. Komput. dan Apl. Untan, vol. 06, no. 03, pp. 43-53, 2018.

[4] F. D. Petruzella, Elektronik Industri. Jakarta: Andi, 2011.

[5] W. Wen, "Introductory Chapter: What is Chemical Sensor," Open access peer-reviewed chapter, 2020. .

[6] I. Sembiring, Timbangen; Dayana, Alat Penguji Material. Jakarta: GUEPEDIA, 2019.

[7] E. Ilham, "Pengertian dan Kelebihan Arduino," IT-Jurnal, 2020. .

[8] P. Seneviratne, Beginning LoRa Radio Networks With Arduino: Build Long Range, Low Power Wireless IoT Networks. Sri Lanka: Apress, 2019.

[9] E. S. Pramukantoro, Internet of Things dengan Python, ESP32, dan Raspberry PI: Teori dan Praktik. Malang: Universitas Brawijaya Press, 2019.

[10] E. D. Widianto, M. S. M. Pakpahan, A. A. Faizal, and R. Septiana, "LoRa QoS Performance Analysis on Various Spreading Factor in Indonesia," ISESD 2018 - Int. Symp. Electron. Smart Devices Smart Devices Big Data Anal. Mach. Learn., 2019. 